
2 Research Square
Preprints are preliminary reports that have not undergone peer review.
They should not be considered conclusive, used to inform clinical practice,
or referenced by the media as validated information.

\title{
The Local Toxicity of Cobalt Chrome implants: A Systematic Review of Preclinical Studies
}

\author{
llaria E. Zais ( $D$ i.zais@yahoo.it) \\ Università degli Studi di Milano \\ Susanna Sammali \\ Università di Bologna \\ Matilde Pavan \\ Università degli Studi di Milano \\ Emanuele Chisari \\ Rothman Orthopaedic Institute at Thomas Jefferson University, Philadelphia, PA, United States \\ Chad A. Krueger \\ Rothman Orthopaedic Institute at Thomas Jefferson University, Philadelphia, PA, United States
}

\section{Systematic Review}

Keywords: Adverse Soft Tissue Reaction, Implant Wear, Metal-on-Metal, Hip Arthroplasty

Posted Date: January 24th, 2022

DOI: https://doi.org/10.21203/rs.3.rs-1240755/v1

License: (c) (i) This work is licensed under a Creative Commons Attribution 4.0 International License. Read Full License 


\title{
Abstract
}

Metal-on-metal total hip arthroplasty prostheses are known to release cobalt and chrome ( $\mathrm{CoCr}$ ) debris. The local accumulation of these ions and nanoparticles can cause adverse local tissue reaction, which can ultimately determine a negative outcome for patients. The aim of our systematic review was to report the latest evidence on the effects of CoCr particles on local soft tissue with a focus on its clinical relevance. PubMed, Embase, and Cochrane Library databases were screened to perform an extensive review. PRISMA guidelines were applied, and the risk of bias was assessed, as was the methodological quality of the included studies. 27 studies were included after applying the inclusion and exclusion criteria. 3 were human ex vivo studies, 24 were preclinical studies, including 21 in vitro and 3 in animal models. The presence of metal ions results in cell damage by reducing cell viability, inducing DNA damage, and triggering the secretion of cytokines, which are responsible for the inflammatory reaction observed in ALTR. CoCr particles released from MoM implants can cause damage to skeletal muscle, the capsule, and provoke osteolysis and inflammation. The cytotoxic and genotoxic damages, as well as the interaction with the immune system, affect the success of the arthroplasty and lead to a higher rate of revision surgeries.

Statement of clinical significance: Ions released from the wear of Metal-on-Metal implant are significantly associated with soft tissue damage, and other local adverse reaction. Multiple mechanistic reasons are proposed.

\section{Introduction}

Total hip arthroplasty (THA) is one of the most successful, and frequently performed, surgical interventions in orthopaedic surgery ${ }^{1,2}$. Metal on metal (MoM) THA prostheses were developed to face the need for bearing surfaces with lower wear, which can ultimately last longer without the need of revision ${ }^{3,4}$. However, despite MoM implants showing improved corrosion resistance compared to alternative articulation surfaces for THAs, it has been documented that the components of MoM prostheses, when in contact with host tissue and joint fluid, undergo tribocorrosion due to the combined action of mechanical loading and chemical corrosion ${ }^{5}$. As a result of this corrosion, soluble ions and wear particles (namely Cobalt (CO) and $\mathrm{Chromium} \mathrm{(Cr)} \mathrm{)} \mathrm{are} \mathrm{released} \mathrm{in} \mathrm{the}$ area surrounding the implant and into systemic circulation ${ }^{6-10} 11$.

These particles are increasingly recognised as both local and systemic toxic substances ${ }^{12}$ based on the alterations to native host tissues they produce and the increased presence of chemokines and cytokines due to the continuous recall of macrophages in response to their presence ${ }^{13-16}$. Strong evidence has confirmed that the local toxicity of these particles and ions is associated with adverse local tissue reaction (ALTR), adverse reaction to metal debris (ARMD), inflammatory pseudotumors and local osteolysis ${ }^{8,16-20}$. Although these diseases may partly explain the higher revision rates of MoM prosthesis, low-grade inflammation seems to be contributing to the development of loosening via a Trojan horse mechanism ${ }^{12,21-23}$ in which neutrophils and macrophages work as a vector for translocation of bacteria from body site to the surgical site. However, evidence about the correlation between levels of bacterial metabolites and joint deterioration is still inconclusive.

The goal of this paper is to describe the influence of cobalt and chrome ions on the periprosthetic area; identify how immunological activation is associated with increased levels of wear debris; and evaluate the risks of implant failure caused by tribocorrosion. Specifically, we asked three questions: (1) what are the local effects of cobalt and chrome particles released from MoM prosthesis? (2) Do increased levels of cobalt and chrome particles affect the success of the arthroplasty? (3) What are the mechanisms that may lead to early implant failure?

\section{Materials And Methods}

\author{
Study Search Strategy
}

This systematic review was conducted according to the guidelines of the Preferred Reporting Items for Systematic Reviews and Meta-Analyses ${ }^{24}$. A comprehensive search was performed using three medical electronic databases (PubMed, EMBASE, and Cochrane Library) by two independent authors (IZ and SS) from January 2000 to January 3rd, 2022. To achieve the maximum sensitivity of the search strategy, we used the following string (cobalt AND (chrome OR chromium)) AND (local* OR muscle OR tendons OR ligaments OR (soft tissue) OR bone) AND (toxicity OR adverse) AND (implant OR prosthesis OR prostheses OR (total joint arthroplasty) OR (total knee arthroplasty) OR (total hip arthroplasty)) as either keywords or Medical Subject Heading terms. The reference lists of all included articles, previous reviews on the topic, and top hits from Google Scholar were reviewed to further identify potentially relevant studies, which were assessed using the inclusion and exclusion criteria. To avoid overlap with other ongoing review studies, we searched PROSPERO for any similar reviews.

\section{Selection Criteria}

Eligible studies included those investigating the influence of MoM implant, wear particles and Cobalt Chrome ions on local osteoarticular tissues and surrounding soft tissues (e.g. tendons, capsule and muscles). The titles and abstracts were screened by including only clinical studies with any level of evidence published in peer-reviewed journals reporting clinical results in English. We excluded studies reporting only clinical results without investigating the topic mechanistically. Additionally, we excluded studies in which data were not accessible or missing, those without an available full-text article. We also excluded duplicates and studies with poor scientific methodology, assessed through validate risk of bias assessment tool (i.e. SYRCLE tool ${ }^{25}$ and ROBINS ${ }^{26}$ ) . Abstracts, case reports, conference presentations, reviews, editorials, and expert opinions were excluded. Two authors (MP and IZ) performed the search and evaluated the articles independently. An experienced researcher in systematic reviews (EC) resolved cases of doubt. First, each investigator read the abstracts of all articles, selected relevant articles according to the inclusion and exclusion criteria, and compared the results with those of the other investigators. After 4 weeks, the same studies were read again to ensure the investigators agreed about article selection. There was no disagreement among the investigators. One 
investigator (SS) extracted data from the full-text articles into an Excel spreadsheet with structured tables to analyze each study descriptively. Another investigator (CAK) independently double-checked the primary data from all articles. Doubts and inconsistencies were grouped and resolved.

\section{Data Extraction and Criteria Appraisal}

Data were extracted from article texts, tables, and figures using the Population, Intervention, Comparison, Outcome framework 27 and included the title, year of publication, study design, sample size, study population, patient characteristics, intervention and comparator group (where applicable), outcomes, findings, and conclusions. Two investigators (IZ and MP) independently reviewed each article. Discrepancies between the two reviewers were resolved by discussion and consensus.

\section{Risk of Bias Assessment}

A risk of bias assessment of all included clinical studies was performed according to the ROBINS risk of bias tool ${ }^{26}$ (Supplementary materials). This assessment used "low," "moderate," and "high" as judgement keys. "Low" indicated a low risk of bias, "moderate" indicated a moderate risk of bias, and "high" indicated a high risk of bias. The assessment was performed by two authors (IZ and MP) independently. The inter-rater agreement was $89 \%$. Any discrepancy was solved by consensus. The articles were considered to have a moderate (eight articles) or low risk of bias (14 articles). We excluded one article because of a serious risk of bias.

\section{Study Selection}

The initial study search resulted in 560 studies. After reading the abstract and title and abstract and removing duplicates, we selected 45 for full text reading. Ultimately, we selected 15 articles for analysis excluding 30 articles because of topic different $(n=26)$, the article was a review outdated ( $n=3)$ and because of a serious risk of bias $(n=1)$. (Fig. 1). 15 studies were included after applying the inclusion and exclusion criteria. 5 were in vitro human studies. 10 were animal model studies, including 6 in vitro and 4 in vivo.

Figure 1. A PRISMA flowchart of the selection process is showed.

\section{Statistical Analysis}

After extracting the data, continuous data was presented as mean and categorical following the authors preference. As per Cochrane handbook, we initially evaluated the possibility of a meta-analysis, however, after reviewing the data and the heterogeneity of outcomes, follow up, and assessments, together with unreported data we reconsidered our design. Thus, descriptive analysis was performed.

\section{Results}

\section{Immunological activation}

Cobalt and chrome released from MoM implants are associated with the activation of the immune system in the tissues surrounding the prosthesis and the production and migration of pro-inflammatory cytokines, prostaglandins, reactive oxygen species (ROS), degradative enzymes and other factors ${ }^{29-32} 33$.

Five studies analysed the immunological response to metal debris in animal models ${ }^{13,15}$, and human samples ${ }^{14,16,33}$. In vitro, it was found that $\mathrm{Co}^{2+}$ and $\mathrm{Cr}^{3+}$ ions cause a significant migration of TCR+ lymphocytes and CD19+ $(p=0.020)^{13}$, as well as changes in the production and secretion of pro-inflammatory cytokines, such as interleukin-8 (IL-8) and monocyte chemoattractant protein 1 (MCP-1) by macrophages and osteoblasts exposed to wear debris ${ }^{13-16}$. Similar results were reported by Trindade et al. ${ }^{14}$ and Matsui et al. ${ }^{34}$ showing that macrophage activation can be induced by inflammation enhancement through interleukin-6 (IL-6), tumour necrosis factor a (TNF- a) and interleukin-1 (IL-1), all of which were elevated by $\mathrm{Co}^{2+}$ and $\mathrm{Cr}^{3+}$ ions. In addition, it was observed a dose-dependent increase in TNF-a release in mouse macrophages after being exposed to $\mathrm{Cr}^{3+}$ and $\mathrm{Co}^{2+}(\mathrm{p}<0.001)$ and macrophage inflammatory protein 1a (MIP-1a) ${ }^{13}$. Because of the role of MIP-1a as chemotactic agent for monocytes and macrophages, Tc lymphocytes, B lymphocytes and NK cells, it could be that this protein is one of the key elements responsible for the inflammatory response to cobalt and chrome ions.

\section{Effects on bone metabolism}

The effects of $\mathrm{Co}$ and $\mathrm{Cr}$ wear debris are associated with a greater risk of periprosthetic osteolysis by altering osteoblast function and by stimulating bone reabsorption through osteoclasts activation. The autocrine and paracrine regulation of cytokines may condition the functions of bone cells.

An in vitro study ${ }^{16}$ investigated the effect of cobalt ions on primary human osteoblasts and demonstrated that metal particles induce an enhanced secretion of immediate-early stress chemokines IL-8 $(p<0.005)$ and monocyte chemoattractant protein $1(\mathrm{MCP}-1)(\mathrm{p}<0.005)$, which ultimately result in migration of neutrophils $(p<0.001)$ and monocytes $(p<0.001)$. The dose-dependent release of such pro-inflammatory cells ${ }^{3,35}$ and prostaglandin $E_{2}\left(P G E_{2}\right){ }^{36,37}$ contributes to osteolysis by recruiting leukocytes and osteoclastic cells to the periprosthetic area and by increasing osteoclast differentiation ${ }^{16}$. Studies also observed that cobalt and chrome ions interfere with osteoblast function, further contributing to osteolysis by suppressing osteogenesis ${ }^{7}$ and by altering the differentiation process of mesenchymal stem cells (MSCs) ${ }^{38}$.

Finally, receptor activator of nuclear factor K-B ligand (RANKL) expression was shown to be enhanced in the presence of Co and Cr ions ${ }^{17} 18$. On the other hand, one study ${ }^{15}$ pointed out that the osteolytic mechanism might not be mediated by RANKL-RANK pathway, but rather caused directly by inflammatory cytokines. The evidence supporting the association between metallic wear debris and bone reabsorption is overall based on moderate quality of evidence, with a total low to moderate risk of bias. 


\section{Effects on soft tissues}

The presence of cobalt and chrome wear particles in the periprosthetic area was associated with an increased incidence of inflammatory reactions 7,8 and periarticular soft-tissue damage.

Multiple clinical studies found higher serum ${ }^{7,8}$ and peri-implant accumulation of chrome and cobalt ions compared to controls 8,33 in patients with inflammation of the tissue surrounding the MoM implants. In addition, a trial carried out on a mouse population proved a particle-dependent pseudotumor-like tissue formation ${ }^{2}$; the dose-dependent nature of such process has been confirmed by other preclinical trials ${ }^{39}$. $\mathrm{Co}^{2+}$ ions were found to be the main culprit for inducing histological damage 1,33,40,41 with deleterious effects including: the necrosis and infarction of connective tissues [1], [3], diffused lymphocytic infiltrate ${ }^{2,8,33}$ and scattered aggregates of metal particles within necrotic macrophages ${ }^{2,8,33,42}$. Nevertheless other studies claim for the equal role of both cobalt and chrome in determining oxidative damage and tissue degeneration ${ }^{33}$. One in vitro study ${ }^{39}$ found that human fibroblasts, exposed to CoCr ions, were induced by those particles to transition into a hypoxia-like state, therefore releasing free radicals and causing further tissue damage.

However, patients' characteristics, such as different PDs (population doublings, a molecular index of cellular senescence), ${ }^{43}$ as well as implant peculiarities, such as a lower loading surface ${ }^{44}$ were found to be variables that may affect the soft tissue degeneration process.

\section{Discussion}

In our review we report evidence of an association between metallic debris released from MoM implants and an increased incidence of inflammatory reaction ${ }^{13-16}$, osteolysis ${ }^{3,7,35,45}$ and damage to the skeletal muscle ${ }^{33,39,40}$. While, the toxicity of metal implants has been confirmed both in vitro and in vivo studies, controversial data exist on the causal relationship between a high $\mathrm{Co}^{2+}, \mathrm{Co}^{3+}$, and chrome ions concentration and local damage. What emerged from our analysis is that all studies are unanimous in affirming that the type and extent of the biological response are dose-dependent to the ion levels deriving from the process of tribocorrosion occurring over time in MoM implants, thereafter higher ion levels can cause greater and more serious reactions.

\section{$\mathrm{Cr}^{3+}$ and $\mathrm{Co}^{2+}$ and risk of adverse local reactions}

Our findings suggest that immunological modifications are associated with a higher risk of adverse local reactions.

The exposure of periprosthetic tissues to byproducts of wear is associated with morphology changes in macrophages ${ }^{14,33}$, immunological activation with secretion of chemotactic agents ${ }^{13-16}$, T-cell lymphopenia $(p=0.024)^{46}$ and hypersensitivity ${ }^{13}$, resulting in a massive production of pro-inflammatory cytokines including IL-1, TNF-a, IL-2, interferon (IFN), and RANKL ${ }^{34,47,48}$. Scharf et al. ${ }^{33}$, through histological analysis of periprosthetic tissue taken during hip revision surgeries, demonstrated a macrophagic and lymphocytic infiltrate in the perivascular space which are often associated with tissue necrosis / infarction; similar results were reported by other works ${ }^{2,8}$.

The exposure of macrophages to $\mathrm{Co}^{2+}$ ions can induce alterations, such as a metabolic shift from oxidative phosphorylation to aerobic glycolysis, through the stabilization of HIF-1a (hypoxia inducible factor 1a), possibly playing a key role in the pro-inflammatory response ${ }^{49}$. The activation of HIF-1a normally occurs in hypoxic conditions to assure cell survival and it promotes the formation of new blood vessels as well as haematopoiesis ${ }^{37,50}$. As a consequence to the stabilization of hypoxia inducible factor due to cobalt ions, an increased production of IL-1, TNF-a and vascular endothelial growth factor (VEGF) was observed: these data, taken altogether, suggest that hypoxic stress induced by cobalt can induce cell death.

The combination of metal ion toxicity and hypersensitivity could explain the onset of necrosis, aseptic lymphocytic vasculitis-associated lesion (ALVAL), ALTR or adverse reaction to metallic debris (ARMD) ${ }^{19,51,52}$. While metal ion toxicity mechanisms have been widely investigated, the molecular pathway(s) that lead to metal hypersensitivity reactions are still not clear: apparently the ion can conjugate with the HLA-peptide complex and generate structural modifications that are subsequently recognised by T-cell receptor, triggering the immune reaction ${ }^{53}$.

Ultimately, a growing body of evidence showed a common feature in the periarticular tissues when high levels of Co and Cr ions are present- the collection of lymphocytes and increased vascularity, characteristics that are usually associated with type IV hypersensitivity. It are these changes that lead to the formation of pseudotumors found surrounding MoM implants.

We strongly encourage further human studies on the mechanisms that underly metal hypersensitivity reactions, to assess their role in the pathogenesis of ARMD, ALVAL and ALTR, in order to find potential molecular targets.

\section{$\mathrm{Cr}^{3+}$ and $\mathrm{Co}^{2+}$ and risk of aseptic loosening}

Aseptic loosening was found to be the main cause to implant failure for MoM THA implants ${ }^{12,54,55}$ and it was seen to be dependent on a variety of immunological modifications that induce osteolysis, as well as damages to the skeletal muscle and the capsule. Debris travelling in the joint fluid can react with any area of the bone and is capable of activating macrophages to initiate an inflammatory reaction, which finally endanger long-term implant stability.

As emerging studies are confirming, the mechanisms by which metal ions may cause osteolysis are indirect: the raise of cytokines, such as IL-1, IL-6, PGE 2 , RANKL and TNF- $\mathrm{a}$, is the main responsible for stimulating osteoclast activation ${ }^{14,15}$, altering MSCs differentiation ${ }^{35}$ and inhibiting osteoblast activity ${ }^{7}$ : when there is insufficient bone to sustain standard loads, the residual bone is more likely to withstand ulterior damage. The metallic ions, through cytokines, are also able to enhance the binding activity of the RANK-ligand to the RANK receptor on osteoclasts, promoting bone reabsorption ${ }^{17,18}$. In addition $\mathrm{Cr}^{3+}$ and $\mathrm{Co}^{2+}$, known as genotoxic agents ${ }^{56}$, can inhibit type-1 collagen gene expression from osteoblastic cells ${ }^{36}$, preventing them from rebuilding new bone.

Page $4 / 9$ 
Thereby, debris from the wear of MoM THA implants results in a local chronic inflammatory and foreign body reaction, which may lead to persistent synovitis resulting in joint pain and swelling, periprosthetic osteolysis, implant loosening and pathologic fracture, ultimately turning out in revision.

In order to describe the pathogenesis of these clinical findings, numerous in vitro and in vivo studies, mentioned above, proved the correlation between ions released from MoM implants and their failure. In vitro studies were unanimous in affirming the cytotoxic and genotoxic effects of CoCr ions, while in vivo studies remain speculative, due to the characteristics of patients which constitute themselves a elevate risk of bias, considering their comorbidities and their different PDs ${ }^{43}$.

\section{$\mathrm{Cr}^{3+}$ and $\mathrm{Co}^{2+}$ and risk of infection}

Although being uncommon, infections represent a cause of revision or resection arthroplasty. The pathogenesis of this serious event consists of interactions among the implant, the host's immune system and the microorganism involved.

Revisions due to infections were analysed 12,21,23,55,57, and an interesting finding of our work was that emerging studies claimed that the periprosthetic accumulation of neutrophils might cause infection via a "Trojan horse" mechanism ${ }^{21-23}$ and therefore partly explain the higher rates of infection in MoM implants. The aforementioned immunological alterations, due to metallic debris, lead to increased production of pro-inflammatory chemokines and cytokines, which trigger augmented endothelial synthesis of vascular and intercellular adhesion molecules (VCAM and ICAM), as well as vascular permeability, allowing cells to escape to the extravascular compartment ${ }^{58,59}$. If these changes occur, neutrophils engulfed with intestinal MRSA ${ }^{59}$ can travel to periprosthetic tissues, possibly provoking prosthetic joint infection (PJI) ${ }^{21-23,55}$. Membrane-permeable antibiotics, according to evidence, seem to be efficient against PJI caused by a Trojan Horse mechanism by killing intracellular pathogens ${ }^{23}$. The low-grade inflammation cascade, which may find its origin in altered gastrointestinal microbiome ${ }^{60}$, likely plays a pivotal role for macrophages and leucocytes migration, from the gut to the implanted joint ${ }^{21,61}$. Therefore, our findings should spur further efforts to investigate the mechanisms that underlie toxin translocation and attention should be focused on the microbiome as a potential therapeutic target.

\section{Conclusions}

The generation of metallic debris from MoM THA prostheses is inevitable, due to the repetitive cyclic loading of their components during use. Our review confirmed that cobalt and chrome ions are implicated in the symbiotic activation of innate immune system as well as the adaptive immune system: these reactions lead to progressive inflammation and osteolysis, ultimately resulting in implant failure and surgical revision. We strongly suggest further research into the pathogenesis of ARMD, early diagnosis and non-operative biological interventions that could prevent the onset of complications and prolong the lifetime of the joint implant devices.

\section{Declarations}

Competing interests: The authors declare no competing interests.

\section{References}

1. Laumonier T, Ruffieux E, Paccaud J, et al. 2019. In vitro evaluation of human myoblast function after exposure to cobalt and chromium ions. J. Orthop. Res. .

2. Paulus A, Ebinger K, Hasselt S, et al. 2017. Biologic effects of metal wear particles and ions in vivo. In: Bone \& Joint Journal Orthopaedic Proceedings Supplement. .

3. Gill HS, Grammatopoulos G, Adshead S, et al. 2012. Molecular and immune toxicity of CoCr nanoparticles in MoM hip arthroplasty. Trends Mol. Med.

4. Learmonth ID, Young C, Rorabeck C. 2007. The operation of the century: total hip replacement. Lancet 370(9597):1508-1519.

5. Shah KM, Wilkinson JM, Gartland A. 2015. Cobalt and chromium exposure affects osteoblast function and impairs the mineralization of prosthesis surfaces in vitro. J. Orthop. Res. .

6. Kanaji A, Orhue V, Caicedo MS, et al. 2014. Cytotoxic effects of cobalt and nickel ions on osteocytes in vitro. J. Orthop. Surg. Res. .

7. Sarhadi VK, Parkkinen J, Reito A, et al. 2015. Genetic alterations in periprosthetic soft-tissue masses from patients with metal-on-metal hip replacement. Mutat. Res. - Fundam. Mol. Mech. Mutagen. .

8. Kwon YM, Ostlere SJ, McLardy-Smith P, et al. 2011. "Asymptomatic” Pseudotumors After Metal-on-Metal Hip Resurfacing Arthroplasty. Prevalence and Metal lon Study. J. Arthroplasty .

9. Skipor AK, Campbell PA, Patterson LM, et al. 2002. Serum and urine metal levels in patients with metal-on-metal surface arthroplasty. In: Journal of Materials Science: Materials in Medicine. .

10. Hartmann A, Hannemann F, Lützner J, et al. 2013. Metal Ion Concentrations in Body Fluids after Implantation of Hip Replacements with Metal-on-Metal Bearing - Systematic Review of Clinical and Epidemiological Studies. PLoS One. 
11. Lhotka C, Szekeres T, Steffan I, et al. 2003. Four-year study of cobalt and chromium blood levels in patients managed with two different metal-on-metal total hip replacements. J. Orthop. Res. .

12. Wyles CC, Van Demark RE, Sierra RJ, Trousdale RT. 2014. High rate of infection after aseptic revision of failed metal-on-metal total hip arthroplasty. In: Clinical Orthopaedics and Related Research. .

13. Baskey SJ, Lehoux EA, Catelas I. 2017. Effects of cobalt and chromium ions on lymphocyte migration. J. Orthop. Res. .

14. Trindade MCD, Lind M, Sun D, et al. 2001. In vitro reaction to orthopaedic biomaterials by macrophages and lymphocytes isolated from patients undergoing revision surgery. Biomaterials .

15. Masui T, Sakano S, Hasegawa Y, et al. 2005. Expression of inflammatory cytokines, RANKL and OPG induced by titanium, cobalt-chromium and polyethylene particles. Biomaterials .

16. Queally JM, Devitt BM, Butler JS, et al. 2009. Cobalt ions induce chemokine secretion in primary human osteoblasts. J. Orthop. Res. .

17. Li D, Wang H, Li Z, et al. 2018. The inhibition of RANKL expression in fibroblasts attenuate CoCr particles induced aseptic prosthesis loosening via the MyD88-independent TLR signaling pathway. Biochem. Biophys. Res. Commun. .

18. MacQuarrie RA, Chen YF, Coles C, Anderson GI. 2004. Wear-Particle-Induced Osteoclast Osteolysis: The Role of Particulates and Mechanical Strain. J. Biomed. Mater. Res. - Part B Appl. Biomater. .

19. Pandit H, Glyn-Jones S, McLardy-Smith P, et al. 2008. Pseudotumours associated with metal-on-metal hip resurfacings. J. Bone Jt. Surg. - Ser. B 90(7):847-851.

20. Campbell P, Ebramzadeh E, Nelson S, et al. 2010. Histological features of pseudotumor-like tissues from metal-on-metal hips. In: Clinical Orthopaedics and Related Research. .

21. Alverdy JC, Hyman N, Gilbert J. 2020. Re-examining causes of surgical site infections following elective surgery in the era of asepsis. Lancet Infect. Dis. 20(3):e38-e43 [cited 2020 Apr 23] Available from: https://linkinghub.elsevier.com/retrieve/pii/S147330991930756X.

22. Thwaites GE, Gant V. 2011. Are bloodstream leukocytes Trojan Horses for the metastasis of Staphylococcus aureus? Nat. Rev. Microbiol. 9(3):215-222 [cited 2020 Apr 23] Available from: http://www.nature.com/articles/nrmicro2508.

23. Hongyi Zhu, Hanqiang Jin, Changqing Zhang TY. 2020. Intestinal methicillin-resistant Staphylococcus aureus causes prosthetic infection via "Trojan Horse" mechanism: Evidence from a rat model. Bone Jt. Res. 9(4):152-161 [cited 2020 Apr 13] Available from:

https://urldefense.com/v3/_https://online.boneandjoint.org.uk/doi/full/10.1302/2046-3758.94.BJR-2019-

0205.R1_;!HnJH5i4VYnf3!oUzYzpN980G5gLGRMvM4oNf30vkK752DBb8NhCOHI2zGfxgF0a19yGf7004PxF7f_yJLAADm\$.

24. Liberati A, Altman DG, Tetzlaff J, et al. 2009. The PRISMA statement for reporting systematic reviews and meta-analyses of studies that evaluate healthcare interventions: explanation and elaboration. BMJ 339(jul21 1):b2700-b2700 Available from: http://www.bmj.com/cgi/doi/10.1136/bmj.b2700.

25. Hooijmans CR, Rovers MM, de Vries RB, et al. 2014. SYRCLE's risk of bias tool for animal studies. BMC Med. Res. Methodol. 14(1):43 [cited 2019 Jan 24] Available from: https://bmcmedresmethodol.biomedcentral.com/articles/10.1186/1471-2288-14-43.

26. Sterne JA, Hernán MA, Reeves BC, et al. 2016. ROBINS-I: A tool for assessing risk of bias in non-randomised studies of interventions. BMJ 355:i4919 [cited 2018 Sep 11] Available from: http://www.ncbi.nlm.nih.gov/pubmed/27733354.

27. Richardson WS, Wilson MC, Nishikawa J, Hayward RS. 1995. The well-built clinical question: a key to evidence-based decisions. ACP J. Club 123(3).

28. Coleman BD, Khan KM, Maffulli N, et al. 2000. Studies of surgical outcome after patellar tendinopathy: clinical significance of methodological deficiencies and guidelines for future studies. Victorian Institute of Sport Tendon Study Group. Scand. J. Med. Sci. Sports 10(1):2-11 [cited 2019 Aug 29] Available from: http://www.ncbi.nlm.nih.gov/pubmed/10693606.

29. Goodman SB, Gibon E, Pajarinen J, et al. 2014. Novel biological strategies for treatment of wear particle-induced periprosthetic osteolysis of orthopaedic implants for joint replacement. J. R. Soc. Interface.

30. Tuan RS, Lee FYI, T Konttinen Y, et al. 2008. What are the local and systemic biologic reactions and mediators to wear debris, and what host factors determine or modulate the biologic response to wear particles? J. Am. Acad. Orthop. Surg. .

31. Wang CT, Lin YT, Chiang BL, et al. 2010. Over-expression of receptor activator of nuclear factor-kB ligand (RANKL), inflammatory cytokines, and chemokines in periprosthetic osteolysis of loosened total hip arthroplasty. Biomaterials .

32. Chamaon K, Schönfeld P, Awiszus F, et al. 2019. Ionic cobalt but not metal particles induces RoS generation in immune cells in vitro. J. Biomed. Mater. Res. - Part B Appl. Biomater. .

33. Scharf B, Clement CC, Zolla V, et al. 2014. Molecular analysis of chromium and cobalt-related toxicity. Sci. Rep. . 
34. Matsui S, Majima T, Mominoki K, et al. 2018. Effects of endoprosthesis head material on acetabular cartilage metabolism: An animal study using crossbred pigs. J. Nippon Med. Sch. .

35. Kwon YM, Xia Z, Glyn-Jones S, et al. 2009. Dose-dependent cytotoxicity of clinically relevant cobalt nanoparticles and ions on macrophages in vitro. Biomed. Mater. .

36. Magone K, Luckenbill D, Goswami T. 2015. Metal ions as inflammatory initiators of osteolysis. Arch. Orthop. Trauma Surg. .

37. Vasconcelos DM, Santos SG, Lamghari M, Barbosa MA. 2016. The two faces of metal ions: From implants rejection to tissue repair/regeneration. Biomaterials.

38. Schröck K, Lutz J, Mändl S, et al. 2015. Co(II)-mediated effects of plain and plasma immersion ion implanted cobalt-chromium alloys on the osteogenic differentiation of human mesenchymal stem cells. J. Orthop. Res. .

39. Madathil BK, Lin Q, Hew CL, Mohanty M. 2010. Hypoxia-like effect of cobalt chromium alloy micro particles on fibroblasts in vitro. J. Orthop. Res. .

40. Xu J, Nyga A, Li W, et al. 2018. Cobalt ions stimulate a fibrotic response through matrix remodelling, fibroblast contraction and release of pro-fibrotic signals from macrophages. Eur. Cells Mater. .

41. Rovetta F, Stacchiotti A, Faggi F, et al. 2013. Cobalt triggers necrotic cell death and atrophy in skeletal C2C12 myotubes. Toxicol. Appl. Pharmacol. .

42. Cunningham BW, Hallab NJ, Hu N, Mcafee PC. 2013. Epidural application of spinal instrumentation particulate wear debris: A comprehensive evaluation of neurotoxicity using an in vivo animal model Laboratory investigation. J. Neurosurg. Spine .

43. Papageorgiou I, Yin Z, Ladon D, et al. 2007. Genotoxic effects of particles of surgical cobalt chrome alloy on human cells of different age in vitro. Mutat. Res. - Fundam. Mol. Mech. Mutagen. .

44. Mostardi RA, Kovacik MW, Ramsier RD, et al. 2010. A comparison of the effects of prosthetic and commercially pure metals on retrieved human fibroblasts: The role of surface elemental composition. Acta Biomater. .

45. Howie DW, Rogers SD, McGee MA, Haynes DR. 1996. Biologic effects of cobalt chrome in cell and animal models. Clin. Orthop. Relat. Res. .

46. Hart AJ, Skinner JA, Winship P, et al. 2009. Circulating levels of cobalt and chromium from metal-on-metal hip replacement are associated with CD8 + Tcell lymphopenia. J. Bone Jt. Surg. - Ser. B .

47. Jacobs JJ, Hallab NJ. 2006. Loosening and osteolysis associated with metal-on-metal bearings: A local effect of metal hypersensitivity? J. Bone Jt. Surg. - Ser. A .

48. Hallab NJ, Anderson S, Caicedo M, et al. 2004. Immune responses correlate with serum-metal in metal-on-metal hip arthroplasty. In: Journal of Arthroplasty. .

49. Salloum Z, Lehoux EA, Harper M, Catelas I. 2020. Effects of Cobalt and Chromium lons on Glycolytic Flux and the Stabilization of Hypoxia-Inducible Factor-1a in Macrophages in Vitro . J. Orthop. Res. .

50. Eltit F, Wang Q, Wang R. 2019. Mechanisms of adverse local tissue reactions to hip implants. Front. Bioeng. Biotechnol. .

51. Willert HG, Buchhorn GH, Fayyazi A, et al. 2005. Metal-on-metal bearings and hypersensitivity in patients with artificial hip joints: A clinical and histomorphological study. J. Bone Jt. Surg. - Ser. A .

52. Davies AP, Willert HG, Campbell PA, et al. 2005. An unusual lymphocytic perivascular infiltration in tissues around contemporary metal-on-metal joint replacements. J. Bone Jt. Surg. - Ser. A.

53. Clayton GM, Wang Y, Crawford F, et al. 2014. Structural basis of chronic beryllium disease: Linking allergic hypersensitivity and autoimmunity. Cell .

54. Judd KT, Noiseux N. 2011. Concomitant infection and local metal reaction in patients undergoing revision of metal on metal total hip arthroplasty. lowa Orthop. J. .

55. Krezalek MA, Hyoju S, Zaborin A, et al. 2018. Can Methicillin-resistant Staphylococcus aureus Silently Travel from the Gut to the Wound and Cause Postoperative Infection? Modeling the "trojan Horse Hypothesis." Ann. Surg. 267(4):749-758 [cited 2020 Apr 13] Available from:

http://www.ncbi.nlm.nih.gov/pubmed/28187042.

56. Tsaousi A, Jones E, Case CP. 2010. The in vitro genotoxicity of orthopaedic ceramic (Al2O3) and metal (CoCr alloy) particles. Mutat. Res. - Genet. Toxicol. Environ. Mutagen. .

57. Mikhael MM, Hanssen AD, Sierra RJ. 2009. Failure of metal-on-metal total hip arthroplasty mimicking hip infection: A report of two cases. J. Bone Jt. Surg. - Ser. A .

58. Sarelius IH, Glading AJ. 2015. Control of vascular permeability by adhesion molecules. Tissue Barriers . 
59. Chakaroun RM, Massier L, Kovacs P. 2020. Gut microbiome, intestinal permeability, and tissue bacteria in metabolic disease: Perpetrators or bystanders? Nutrients .

60. Boer CG, Radjabzadeh D, Medina-Gomez C, et al. 2019. Intestinal microbiome composition and its relation to joint pain and inflammation. Nat. Commun. 10(1):4881 Available from: http://www.nature.com/articles/s41467-019-12873-4.

61. Muraille E, Leo O, Moser M. 2014. Th1/Th2 paradigm extended: Macrophage polarization as an unappreciated pathogen-driven escape mechanism? Front. Immunol. 5(NOV).

\section{Tables}

Table 1 is available in the Supplementary Files section.

\section{Animal studies}

\section{SYRCLE assessment tool}

\begin{tabular}{|c|c|c|c|c|c|c|c|c|c|c|}
\hline Author & Study & $\begin{array}{l}\text { Selection } \\
\text { bias } 1\end{array}$ & $\begin{array}{l}\text { Selection } \\
\text { bias } 2\end{array}$ & $\begin{array}{l}\text { Selection } \\
\text { bias } 3\end{array}$ & $\begin{array}{l}\text { Performance } \\
\text { bias } 1\end{array}$ & $\begin{array}{l}\text { Performance } \\
\text { bias } 2\end{array}$ & $\begin{array}{l}\text { Detection } \\
\text { bias } 1\end{array}$ & $\begin{array}{l}\text { Detection } \\
\text { bias } 2\end{array}$ & $\begin{array}{l}\text { Attrition } \\
\text { bias }\end{array}$ & $\begin{array}{l}\text { Reporting } \\
\text { bias }\end{array}$ \\
\hline Paulus & $\begin{array}{l}\text { Local Biological } \\
\text { Reactions and } \\
\text { Pseudotumor- } \\
\text { Like Tissue } \\
\text { Formation in } \\
\text { relation to } \\
\text { Metal Wear in a } \\
\text { Murine In } \checkmark \text { i } \checkmark \text { o } \\
\text { Model. }\end{array}$ & $\checkmark$ & $\checkmark$ & $x$ & $?$ & $x$ & $x$ & $x$ & $\checkmark$ & $\checkmark$ \\
\hline Matsui & $\begin{array}{l}\text { Effects of } \\
\text { Endoprosthesis } \\
\text { Head Material } \\
\text { on Acetabular } \\
\text { Cartilage } \\
\text { Metabolism: An } \\
\text { Animal Study } \\
\text { Using } \\
\text { Crossbred Pigs. }\end{array}$ & $x$ & $\checkmark$ & $x$ & $?$ & $x$ & $x$ & $x$ & $\checkmark$ & $\checkmark$ \\
\hline Cunningham & $\begin{array}{l}\text { Epidural } \\
\text { application of } \\
\text { spinal } \\
\text { instrumentation } \\
\text { particulate wear } \\
\text { debris: a } \\
\text { comprehensi } \sqrt{ } \text { e } \\
\text { e } \sqrt{ } \text { aluation of } \\
\text { neurotoxicity } \\
\text { using an } \\
\text { in } \sqrt{ } \sqrt{ } \text { o animal } \\
\text { model. }\end{array}$ & $\checkmark$ & $\checkmark$ & $\checkmark$ & $\mathrm{x}$ & $\mathrm{x}$ & $\mathrm{x}$ & $\checkmark$ & $\checkmark$ & $\checkmark$ \\
\hline Custers & $\begin{array}{l}\text { Articular } \\
\text { damage caused } \\
\text { by metal plugs } \\
\text { in a rabbit } \\
\text { model for } \\
\text { treatment of } \\
\text { localized } \\
\text { cartilage } \\
\text { defects. }\end{array}$ & $?$ & $\checkmark$ & $\checkmark$ & $\checkmark$ & $\mathrm{x}$ & $\checkmark$ & $\checkmark$ & $\checkmark$ & $\checkmark$ \\
\hline Masui & $\begin{array}{l}\text { Expression of } \\
\text { inflammatory } \\
\text { cytokines, } \\
\text { RANKL and } \\
\text { OPG induced by } \\
\text { titanium, } \\
\text { cobalt- } \\
\text { chromium and } \\
\text { polyethylene } \\
\text { particles. }\end{array}$ & $?$ & $\checkmark$ & $x$ & $?$ & $x$ & $\checkmark$ & $\checkmark$ & $x$ & $\checkmark$ \\
\hline
\end{tabular}


$1 \checkmark=$ Adequate randomization; $?=$ randomized but no details; $x=$ no evidence of randomization.

$2 \checkmark=$ Baseline characteristics given; $\mathrm{x}=$ baseline characteristics not given .

$3 \checkmark=$ Evidence of adequate concealment of groups; $x=$ no evidence of adequate concealment of groups.

$4 \checkmark=$ Evidence of random housing of animals; ? = unknown housing arrangement.

$5 \checkmark=$ Evidence of caregivers blinded to intervention; $x=$ no evidence of caregivers blinded to intervention.

$6 \checkmark=$ Evidence of random selection for assessment; $x=$ no evidence of random selection for assessment.

$7 \checkmark=$ Evidence of assessor blinded; $x=$ no evidence of assessor blinded.

$8 \checkmark=$ Explanation of missing animal data; $x=$ no explanation of missing animal data.

$9 \checkmark=$ Free of selective reporting based on methods/results; $?=$ insuive reporting; $x$ = selective reporting.

$10 \checkmark=$ Free of other high bias risk; ? = insufficient data to determine risk of other bias.

\section{Figures}

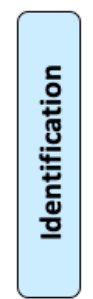

Records identified through database searching $(n=560)$

Records after duplicates removed

$(n=560)$
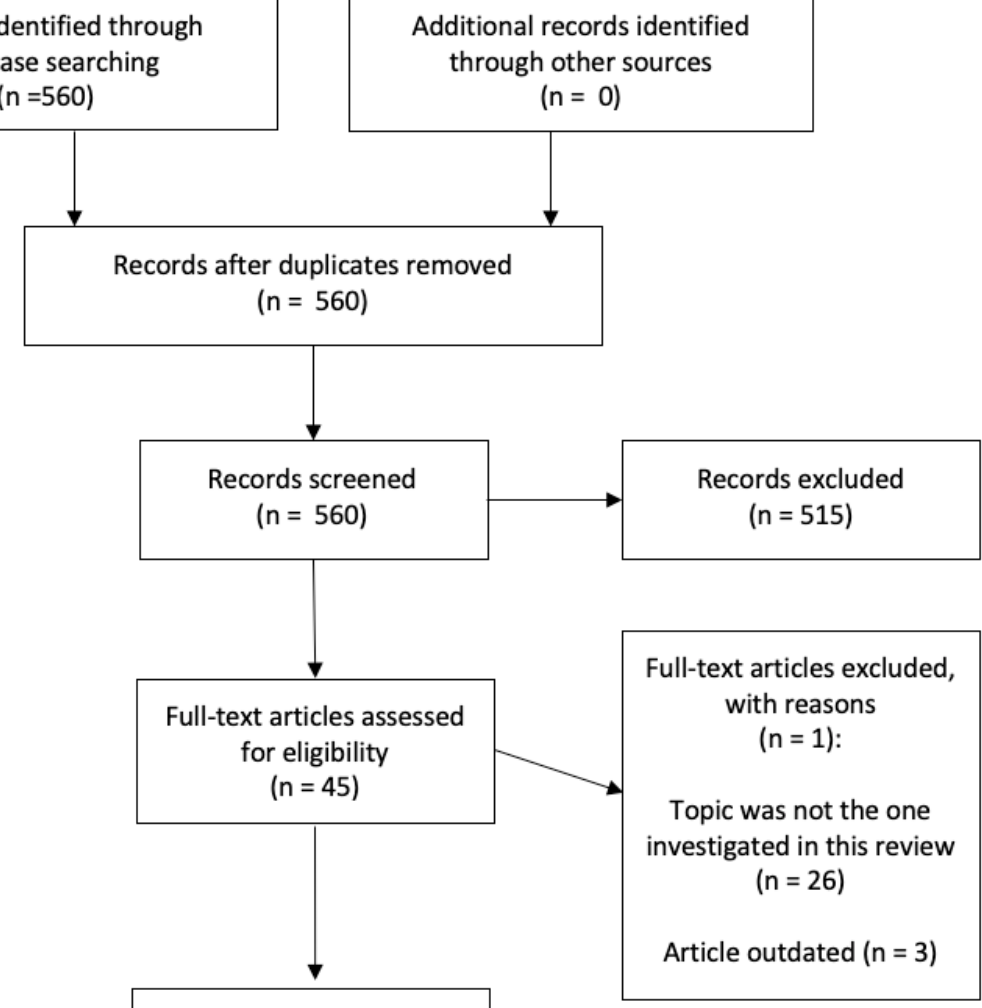

Studies included in qualitative synthesis ( $n=15)$

Figure 1

PRISMA flowchart

\section{Supplementary Files}

This is a list of supplementary files associated with this preprint. Click to download.

- TablesCoCr.docx 